\title{
Hatay İli Havuç Ekim Alanlarında Bulunan Yabancı Ot Türleri, Yaygınlıkları, Yoğunlukları ve Durumlarının Değerlendirilmesi
}

Evaluation of Weed Species, Their Frequencies, Densities and Current Status in Carrot Fields in Hatay Province

\section{İlhan ÜREMİ̧ ${ }^{1}$, Soner SOYLU ${ }^{1 *}$,Şener KURT ${ }^{1}$, E. Mine SOYLU ${ }^{1}$, Erdal SERTKAYA $^{1}$}

\section{$\ddot{\mathbf{O} z}$}

Havuç [Daucus carota L.], yüksek seviyede provitamin A, amino asitler ve diğer besinleri içeren, dünya çapında önemli bir sebzedir. Hatay ili, Türkiye'nin kaliteli ve yüksek miktarda havuç üretiminin yapıldığı üçüncü bölgesidir. Havuç üretimi ve kalitesi gerek tarla gerekse depolama sırasında hastalıklar, zararlılar ve yabancı otlar tarafindan etkilenir. Bu çalışmada Hatay ilinin havuç yetiştiriciliğinin yapıldığı önemli ilçelerinde tesadüfü seçilmiş tarlalarda karşılaşılan yabancı ot türlerinin varlığı, yaygınlığı ve genel durumları 80 havuç tarlasında yapılan sürveyle belirlenmiştir. Bölgede yapılan sürvey sonucunda 26 familyada yer alan farklı 66 cinse ait 78 yabancı ot türü belirlenmiștir. Tespit edilen yabancı ot türleri yoğunluklarına göre sınıflandırıldığında en sik ve yoğunlukta karşılaşılanlar; Cyperus rotundus (Topalak) $>3.00$ adet $/ \mathrm{m}^{2}$, Portulaca oleracea, Amaranthus retroflexus, Sorghum halepense, Alopecurus myosuroides, Amaranthus graecizans, Amaranthus hybridus, Amaranthus spinosus, Avena sterilis, Chenopodium album, Convolvulus arvensis, Cynodon dactylon, Echinochloa colonum, Euphorbia chamaesyce, Medicago spp., Physalis angulata, Prosopis farcta, Silybum marianum, Triticum aestivum, Sinapis arvensis, Trifolium spp., Zea mays ve Xanthium strumarium türlerinin ise $0.10-2.99 \mathrm{adet} / \mathrm{m}^{2}$ yoğunlukta olduğu gözlenmiştir. Aralarında parazitik türlerden Orobanche crenata (beyaz çiçekli canavar otu), Phelipanche ramosa (mavi çiçekli canavar otu)'nın yanısıra, Ipomoea triloba (pembe çiçekli akşamsefası) ve Amaranthus palmeri (dev horozibiği) gibi çok önemli ve istilacı potansiyele sahip 55 farklı yabancı otun yaygınlık seviyesinin ise 0.10 > $\operatorname{adet} / \mathrm{m}^{2}$ olduğu tespit edilmiştir. Çalışmada kaydedilen bir diğer önemli gözlem C. rotundus bitkilerinin üzerinde saptanan ve yabanc1 otun biyolojik mücadelesinde kullanılma potansiyeli olan pas hastalık etmeni Puccinia romagnoliana Maire \& Sacc.'nın bazı sürvey alanlarındaki topalak bitkileri üzerinde yaygın ve şiddetli şekilde bulunmasıdır. Sonuçlar $O$. crenata, $P$. ramosa, I. triloba ve A. palmeri gibi çok önemli ve istilacı potansiyele sahip yabancı ot türlerinin bölgede yayılma riskinin bulunduğunu ortaya koyarken, bazı bölgelerde yaygın olarak gözlenen pas hastalığı etmeninin havuç tarlalarının en önemli yabancı otlarından olan topalak ile mücadelede kullanılma potansiyelinin bulunduğu düşünülmektedir.

Anahtar kelimeler: Hatay, havuç, canavar otu, Amaranthus palmeri, yabancı ot, sürvey

\begin{abstract}
Carrot [Daucus carota L.] is an important vegetable worldwide, which contains high levels of provitamin A, amino acids and other nutrients. Hatay province is the third province of the Turkey leading high amount and quality carrot production. Carrot crop production is hampered by diseases, pests and weeds which reduce production and quality of carrot in the fields and during storage. This study was conducted in major carrot growing districts of Hatay province for determination of densities, frequencies and current statues of major weeds species in randomly selected 80 carrot fields in surveyed districts between August 2018-October 2019. During weed surveys, a total of 78 plant species, belonging to 26 different families and 66 genera, including 2 parasitic plants, 41 winter, 32 summer, 3 summer-winter species and 16 grasses, 60 broad leaved were determined. According to life cycles the weeds were classified as, 9 species as perennial, 57 species as annual, 3 species as biennial, 3 species as annualperennial and 4 species as annual-biennial. According to their density recorded, Cyperus rotundus (purple nutsedge)

\footnotetext{
${ }^{1 *}$ Sorumlu Yazar/Corresponding Author: Soner Soylu, Hatay Mustafa Kemal Üniv. Ziraat Fak., Bitki Koruma Böl., Hatay. Türkiye E-mail: soylu@ @mu.edu.tr, (iD) OrcID: 0000-0003-1002-8958

${ }^{1}$ İlhan Üremiş, Hatay Mustafa Kemal Üniv. Ziraat Fak., Bitki Koruma Böl., Hatay. Türkiye E-mail: iuremis@mku.edu.tr, (D) OrcID: 0000-0001-5937-9244 ${ }^{1}$ Şener Kurt, Hatay Mustafa Kemal Üniv. Ziraat Fak., Bitki Koruma Böl., Hatay. Türkiye E-mail: kurt@mku.edu.tr, (DD OrcID: 0000-0003-4545-5968 ${ }^{1}$ E. Mine Soylu, Hatay Mustafa Kemal Üniv. Ziraat Fak., Bitki Koruma Böl., Hatay. Türkiye E-mail: kurt@mku.edu.tr, (iD) OrcID: 0000-0001-5961-0848 ${ }^{1}$ Erdal Sertkaya, Hatay Mustafa Kemal Üniv. Ziraat Fak., Bitki Koruma Böl., Hatay. Türkiye E-mail: kurt@mku.edu.tr, (D) OrcID: 0000-0001-9956-943X Atıf/Citation: Üremiş, İ., Soylu, S., Kurt, Ş., Soylu, E.M., Sertkaya, E. 2020. Hatay İli Havuç Ekim Alanlarında Bulunan Yabancı Ot Türleri, Yaygınlıkları, Yoğunlukları ve Durumlarının Değerlendirilmesi Tekirdağ Ziraat Fakültesi Dergisi, 17(2), 211-228

(CBu çalışma Tekirdağ Namık Kemal Üniversitesi tarafından Creative Commons Lisansı (https://creativecommons.org/licenses/by-nc/4.0/) kapsamında yayınlanmıştır. Tekirdağ 2019
} 
was $>3.00$ plant $/ \mathrm{m}^{2} ;$ Portulaca oleracea, Amaranthus retroflexus, Sorghum halepense, Alopecurus myosuroides, Amaranthus graecizans, Amaranthus hybridus, Amaranthus spinosus, Avena sterilis, Chenopodium album, Convolvulus arvensis, Cynodon dactylon, Echinochloa colonum, Euphorbia chamaesyce, Medicago spp., Physalis angulata, Prosopis farcta, Silybum marianum, Triticum aestivum, Sinapis arvensis, Trifolium spp., Zea mays, Xanthium strumarium were at the density of 0.10-2.99 plant $/ \mathrm{m}^{2}$. The density level of 55 different weeds, including important weed species such as parasitic Orobanche crenata (bean broomrape), Phelipanche ramosa (hemp broomrape) and invasive Ipomoea triloba (three-lobe morning glory) and Amaranthus palmeri (palmer amaranth), was found at the density of $0.10>$ plant $/ \mathrm{m}^{2}$. Another important observation recorded in the study is the widespread and severe presence of rust disease agent Puccinia romagnoliana Maire \& Sacc. which has potential to be used as biological control agent on $C$. rotundus. Overall the results suggested that there is a risk of spreading of $O$. crenata, P. ramosa, I. triloba and A. palmeri which have invasive potential in the region. Results also pointed out potential of rust disease, which was commonly observed in some regions, to be used in the biological control of purple nutsedge which is the most important and common weed species detected in the region.

Keywords: Hatay, carrot, broomrape, Amaranthus palmeri, weeds, survey 


\section{Extendend Summary}

Carrot [Daucus carota L.] is an important vegetable worldwide, which contains high levels of provitamin A, amino acids and other nutrients. Hatay province is the third province of the Turkey leading high amount and quality carrot production. Carrot crop production is hampered by diseases, pests and weeds which reduce production and quality of carrot in the fields and during storage. This study was conducted in major carrot growing districts of Hatay province for determination of densities, frequencies and current statues of major weeds species in randomly selected 80 carrot fields in surveyed districts during August 2018 and October 2019 growing season. During weed surveys, a total of 78 plant species, belonging to 26 different families and 66 genera, including 2 parasitic plants, 41 winter, 32 summer, 3 summer-winter species and as 16 grasses, 60 broad leaved. According to life cycles the weeds were classified as, 9 perennial, 57 annual, 3 biennial, 3 annual-perennial and 4 annual-biennial were determined. Most common 3 families were Poaceae (15), Asteraceae (14) and Brassicaceae (6). According to their density and frequency results, Cyperus rotundus (purple nutsedge) was $>3.00 \mathrm{plant} / \mathrm{m}^{2}$; Portulaca oleracea , Amaranthus retroflexus, Sorghum halepense, Alopecurus myosuroides, Amaranthus graecizans, Amaranthus hybridus, Amaranthus spinosus, Avena sterilis, Chenopodium album, Convolvulus arvensis, Cynodon dactylon, Echinochloa colonum, Euphorbia chamaesyce, Medicago spp., Physalis angulata, Prosopis farcta, Silybum marianum, Triticum aestivum, Sinapis arvensis, Trifolium spp., Zea mays, Xanthium strumarium were at the density of 0.10-2.99 plant $/ \mathrm{m}^{2}$. The density level of 55 different weeds, including important invasive weed species such as Orobanche crenata (bean broomrape), Phelipanche ramosa (hemp broomrape), Ipomoea triloba (threelobe morning glory) and Amaranthus palmeri (palmer amaranth), was found to be at the density of $0.10>$ plant $/ \mathrm{m}^{2}$. Amongst weed species determined during surveys, 34 weed species were found as their frequency ratios over 12.5\%. Cyperus rotundus, Amaranthus hybridus, Amaranthus retroflexus, Chenopodium album, Convolvulus arvensis, Echinochloa colonum, Physalis angulata, Portulaca oleracea, Sorghum halepense, Xanthium strumarium were the most common weeds. Due to the insufficient mechanical control and lack of an effective herbicide, Cyperus rotundus is in the forefront in terms of its density and frequency, therefore local farmers were unable to control this weed species. However, during survey in some carrot fields, fungal rust disease agent Puccinia romagnoliana Maire \& Sacc., as the potential biological control agent reported for this weed species, was intensively observed in some of the surveyed carrot fields. This disease agent was found to control nudsedge plants in the previously surveyed fields during following surveys. Another important observation recorded in the study is the first report of the presence of invasive weed species Amaranthus palmeri S. Watson (palmer amaranth) and Ipomoea triloba L. (three-lobe morning glory) in the surveyed carrot fields in Turkey. This study is also first report of the presence of two different parasitic weed species of broomrape, Orobanche crenata (bean broomrape) and Phelipanche ramosa (hemp broomrape) in the carrot fields in Turkey in low frequencies and densities. The low quality and yield caused by these parasitic plants in this field suggest that presence of these parasitic plants may cause serious problems in the future unless the necessary precautions are taken. In addition, the presence of the invasive weed species A. palmeri should be concerned not only for carrots but also for all summer crops. 
Üremiş\& Soylu\& Kurt\& Soylu\& Sertkaya

Hatay ili havuç ekim alanlarında bulunan yabancı ot türleri, yaygınlıkları, yoğunlukları ve durumlarının değerlendirilmesi.

Ana vatanı Afganistan, İran ve Pakistan'ın içinde yer aldığı Orta Asya ve Güney Asya ile Türkiye olan havuç (Daucus carota L.) Umbelliferae (Apiaceae) familyasına bağlı, etli sulu kökleri yenen, iki yıllık bir serin iklim bitkisidir (Rubatzky ve ark., 1999; Safadi, 2008). Az 1şık, düşük sıcaklık ve toprak neminin uygun olduğu topraklarda iyi gelişim göstermektedir (Sermenli, 2012). Özellikle A vitamini kaynağı olup bunun yanında B1-B2 vitaminleri ve mineral içeriği ile yüksek besin değeri taşımaktadır (Munro ve Small, 1997). Bu özelliklerinden dolayı dünyanın her yerinde yetiştirilen ve insan beslenmesinde önemli yeri olan ve üretimi tohumla yapılan sebzelerden biri olup lezzetinin yanında insan sağlığı açısından da önemli yararları bulunmaktadır (Yanmaz, 1994; Peters, 2006). Üretilen havuçların büyük bir kısmını portakal veya turuncu renkli, az bir kısmını ise siyah renkli havuçlar oluşturmaktadır (Vural ve ark., 2000).

Dünya Gıda ve Tarım Örgütü (FAO) 2017 yılı havuç üretim verilerine göre, Çin 20.274.393 tonla ilk sırada yer alırken bu ülkeyi 2.249.737 ton ile Özbekistan ve 1.805.787 ton ile Rusya izlemekte olup Türkiye ise 571.301 ton ile 9. sırada yer almıştır (Anonymous, 2017). Ülkemizde 2018 yılında ise toplam 123.478 dekar alanda 642.837 ton havuç üretimi yapılmış olup, Hatay ili 21.550 dekar alanda 58.190 ton üretim miktarı ile ülkemizin önemli havuç ekim alanlarından olan Konya ve Ankara illerinden sonra üçüncü sırada yer almaktadır (Anonim, 2017). Hatay'da iklim şartlarının uygunluğu, ihracat edilebilirliği, piyasa özelliği ve üreticilerin kış aylarında geçim kaynağı olması nedeniyle havuç üretimi gün geçtikçe artmaktadır (Sermenli, 2012). Hatay ilinde havuç üretiminin en yoğun yapıldığg yer olan Amik Ovası'nda bulunan Kırıkhan ilçesinde 19.000 dekar alanda 47.500 ton havuç üretimi yapılmış olup bunu 2.100 dekar alanda 9.450 ton üretimle Reyhanlı, 230 dekar alanda 690 ton üretimleri ile Antakya ilçeleri takip etmiştir (Anonim, 2017).

Kırıkhan ilçesinin ekolojisinin uygun olması nedeni ile Ağustos ayı başında başlayan tohum ekimi kademeli olarak Kasım ayı sonuna kadar devam etmekte, Aralık ayı itibari ile başlayan hasat ise Nisan sonuna kadar sürmektedir (Sermenli, 2012). Ülkemiz ekonomisi için önemli bir yere sahip olan havuç bitkisinin verim ve kalitesi birçok biyotik ve abiyotik faktörler tarafindan etkilenmektedir.

Hatay ilinde son 10 yıl içerisinde ekim alanı 2 katı artış gösterirken, üretimde bu artış katsayısı gözlenememiştir. Havuç ekimini ve verimini kısıtlayan ana faktörlerin başında hastalık, zararlı ve yabancı otlar gelmektedir. Dünyanın bir çok ülkesinde havuç ekim alanlarında sorun olan hastalık zararlı ve yabancı otlar üzerine çalışmalar bulunurken, ülkemizde havuç bitkisinde sorun olan hastalık, zararlı ve yabancı otlar konusunda oldukça kısıtlı çalışmalar bulunmaktadır (Erciş ve ark., 1995; Kurt ve ark., 2004; Soylu ve ark., 2005; Tülek, 2010; Uysal, 2012; Çabuk, 2014; Sertkaya, 2014). Havuç alanlarında yabancı otlarla ilgili Türkiye'de sadece bir adet yabancı ot survey çalışması bulunmaktadır. Bu çalışma 1988-1991 yılları arasında Ankara'da yürütülmüş olup yapılan surveylerde 34 yabancı ot türü saptanmış ve bunlar içerisinde en yaygın ve yoğun olarak bulunan üç tür, sirasiyla; Amaranthus retroflexus (\% 93,4 ve 2,78 adet $\left./ \mathrm{m}^{2}\right)$, Portulaca oleracea $\left(\% 89,1\right.$ ve 2,65 2,78 adet $/ \mathrm{m}^{2}$ ) ve Chenopodium album (\% 86,6 ve 3,19 2,78 adet $/ \mathrm{m}^{2}$ ) (Erciş ve ark., 1995)'dur.

Havucun özellikle ilk gelişim dönemlerindeki gelişim hızının düşük olması, köklerinin zayıf - yüzlek olması ve yapraklarının ince ve küçük olması nedeniyle yabancı otlara karşı rekabet gücü düşük bitkiler arasında önlerde gelmektedir (OMAFRA, 2008). Havuç'un ana zararlılarından birisi de yabancı otlardır (Bhullar ve ark., 2015). Yabancı otlardan topalak (Cyperus rotundus L.)'ın havuçta meydana getirdiği ürün kaybının \% 39-50 arasında olduğu bildirilmektedir (William ve Warren, 1975). Yabancı otlar kültür bitkileri ile su, besin maddeleri ve 1şık yönünden rekabete girmek suretiyle ekonomik öneme sahip ürünlerde \%28-78'lere varan oranlarda verim ve kalite kayıplarına neden olmaktadır (Oerke ve ark., 1994; Bhuller ve ark., 2015; Zimdahl, 2018; Üremiş ve Uludağ, 2020). Canavar otunun ürün ve kaliteye etkisi konusunda bir çalışmaya rastlanmamıştır, ancak bu zararın yoğunluğa bağlı olarak çok yüksek oranlarda gelişebileceği tahmin edilmektedir. Yabancı otlarla mücadelede esas alınması gereken kritik periyot olarak havucun çıkışından itibaren 3-6 hafta arası olarak bildirilmektedir (Bhullar ve ark., 2015). Swanton ve ark., (2010) kritik periyodun havucun yetişme dönemine bağlı olarak 414-930 GDD (günlük gelişme derecesi) arasında olduğunu bunun da havucun 4-12 yapraklı dönemine karşılık olduğuna dikkat çekmektedir, ayrıca havuçta oluşan ürün kaybının \% 4.87 ila \%100 arasında değiştiği bildirilmektedir. Ojedo ve Garay (2017) yabancı otlardan dolayı maksimum ürün kaybının \% 93.6 olduğunu, kritik periyodun ise yabancı otlara ve havuç çeşitlerine bağlı olarak yabancı otların çıkışından itibaren 19-70 gün arasında değiştiğini belirtmektedir. Yabancı otlar ürün ve kalite azalması yanında, birçok hastalık ve zararlıya konukçuluk yapmakta, içerdiği zararlı bileşikler birçok canlıda ölüme varabilen zehirlenmelere yol açabilmekte, yetiştiricilikle ilgili işlemlerin yapılmasını ve hasadı güçleştirmektedir. Yabancı ot tohumları hasat sırasında kültür bitkilerinin tohumlarına karışmak suretiyle ürünlerin besin değerini düşürmelerinin yanı sıra, ürünlerin tohumluk kalitesinin düşmesine de neden olurlar (Güncan, 2016; Zimdahl, 2018). Bu nedenle uygun yöntemler kullanılarak yabancı otlarla mücadele kaçınılmaz olmaktadır. Tarımın sürdürülebilirliğinin sağlanması, çevrenin korunabilmesine yönelik hazırlanan Entegre Mücadele programlarından beklenen başarı ancak söz konusu hedef alanlardaki yabancı ot florasının belirlenmesi ile mümkündür (Uludağ ve ark., 2018). Bölgedeki yabancı ot florası bilinmeden 
entegre mücadele programlarının, yürütülmesinin zor olmasının yanısıra, programdan sağlıklı ve başarılı sonuçların beklenmesi mümkün değildir (Karaca, 2010).

Hatay ilinde üretimi yapılan havuç alanlarında son günlerde gerek yetiştiriciler gerekse resmi kurum personelleri tarafından havuç alanlarında önemli verim kayıplarına neden olan yabancı otların varlığına dikkat çekilmiş olup, bölgedeki havuç alanlarındaki yabancı ot sorunlarının ortaya konulması için kapsamlı bir araştırma yapma gerekliliği ortaya çıkmıştır.

Bu çalışma ile Hatay ilinin önemli havuç ekim alanlarında kalite ve ürün kaybına neden olan etmenlerden yabancı ot türlerinin teşhisleri, yaygınlıkları, yoğunluklarının belirlenmesinin yanı sıra sürvey yapılan tarlalarda yabancı otların genel durumlarının ortaya konulması amaçlanmıştır.

\section{Materyal ve Yöntem}

\section{Sürvey çalışması, örnekleme yöntemleri ve örneklerin alınması}

Hastalık, zararlı ve yabancı ot sürvey çalışmaları 2017 yılı Tarım İl Müdürlüğü verileri göz önünde alınarak yapılmıştır. Çalışmalar, Hatay ilinde havuç yetiştiriciliğinin (en yoğun ekim alanlarının yer aldığı Antakya, Kırıkhan, Kumlu ve Reyhanlı ilçelerinde 15 Ağustos 2018 ve 15 Ekim 2019 ayları arasında 80 tarlada yapılmıştır.

Çizelge 1. Hatay ili havuç ekim alanları, üretim miktarı ve sürvey yapılan tarla sayısı (Anonim 2017)

Table 1. Total production amount and harvesting area of carrot, and number of surveyed carrot fields in Hatay province (Anonim 2017)

\begin{tabular}{lccc}
\hline İlçeler & Üretim (ton) & Ekim Alanı (da) & $\begin{array}{c}\text { Tarla Sayısı } \\
\text { (adet) }\end{array}$ \\
\hline Kırıkhan & & 19.000 & 44 \\
\hline Reyhanlı & 47.500 & 2100 & 12 \\
\hline Antakya & 9.450 & 230 & 12 \\
\hline Kumlu & 690 & 220 & 12 \\
\hline Toplam & 550 & $\mathbf{2 1 . 5 5 0}$ & $\mathbf{8 0}$ \\
\hline
\end{tabular}

$\mathrm{Bu}$ amaca yönelik hazırlanan survey programı 2017 Türkiye İstatistik Kurumu verileri doğrultusunda hazırlanmış olup, her ilçe için yapılması gereken örnekleme sayısı toplam ekiliş alanı üzerinden "tartılı ortalama yöntemi” (Bora ve Karaca, 1970) kullanılarak belirlenmiştir (Çizelge 1). Yapılan hesaplamada Kırıkhan haricindeki ilçelerde yapılması gereken survey sayılarının düşük sayıda olması nedeniyle bu ilçelerdeki survey en az 12 tarlayı kapsayacak şekilde düzenlenmiştir. Ancak, Reyhanlı ve Kumlu ilçelerindeki havuç tarlalarında bitki hastalıkları ve zararlılarda mevcut proje kapsamında takip edildiği için daha fazla sayıda survey yapılmıştır. Yabancı ot türlerinin teşhisleri ve bulunuş oranları gerek çember atma gerekse tarla içinde tarlayı temsil edecek şekilde rastgele gezmek suretiyle belirlenmiştir. Çalışmada Kırıkhan ilçesi merkez alınarak survey alanlarına doğru gidilerek her 3 km'de bir tesadüfi olarak durulmuş ve en yakın havuç tarlasına girilerek tarlalarda kenar tesirinden kurtulmak amacıyla çerçeve atımına 3-5 m içerden başlanmıştır. Havuç tarlasında 1 da'lık alan dikkate alınarak ve her tarlada rastlantısal olarak dört defa $0.5 \mathrm{~m} \mathrm{x} 0.5 \mathrm{~m}=0.25 \mathrm{~m}^{2}$ lik ahşap çerçeve atılarak çerçeveler içerisindeki yabancı otların türleri ve yoğunlukları $\left(\mathrm{adet} / \mathrm{m}^{2}\right.$ ) kaydedilmiştir (Orel, 1996). Tarlada teşhisi yapılamayan yabanıı otların herbaryumlarının yapılması için laboratuvara getirilmiş ve herbaryum tekniğine göre (Özer ve ark., 1998) kurutulmuştur. Teşhis için toplanan örnekler MKÜ Ziraat Fakültesi Bitki Koruma Bölümü Herbaryumunda saklanmıştır. Bitki örneklerinin tanısı Davis (1965-1988), isimlendirilmeleri Uluğ ve ark. (1993)'e göre yapılmıştır. 
Üremiş\& Soylu\& Kurt\& Soylu\& Sertkaya

Hatay ili havuç ekim alanlarında bulunan yabancı ot türleri, yaygınlıkları, yoğunlukları ve durumlarının değerlendirilmesi.

Rastlama sıklıklarının belirlenmesinde aritmetik yüzde esas alınarak hesaplama yapılmıştır. Bunun için aşağıdaki formüller kullanılmıştır (Odum, 1971).

$\%$ Rastlama Siklığ $1(\mathrm{RS})=100 *(\mathbf{n} / \mathbf{m})$

m: Örnekleme yapılan toplam tarla sayısı; n: Yapılan örneklemenin kaçında o tür ile karşılaşıldığg

Hesaplanan yabancı ot yaygınlıklarının değerlendirilmesinde ise Pamukoğlu (2011)'dan uyarlanan skala kullanılmıştır. Kullanılan skalaya göre; Çok Rastlanan (ÇR) > \% 50.0; Orta Rastlanan (OR) \% 25.0 - \% 49.9; Az Rastlanan (AR); \% 12.5 - \% 24.9; Nadir Rastlanan (NR) <12.5 olarak değerlendirilmiştir.

Yabancı otların yoğunluklarının (bitki $/ \mathrm{m}^{2}$ ) belirlenmesinde; bir tarlada her bir yabancı ot için yapılan sayımlar sonucu elde edilen değer o tarlada sayım yapılan toplam alana bölünmesi ile hesaplanmıştır. Hesaplanan yabancı ot yoğunluklarının değerlendirilmesinde ise Pamukoğlu (2011)'dan uyarlanan skala ile ifade edilmiştir. Buna göre; A:>3.00 adet/ $\mathrm{m}^{2}$; B: 2.00-2.99 adet/ $\mathrm{m}^{2}$; C: 1.00-1.99 adet/ $\mathrm{m}^{2}$; D: 0.10-0.99 adet $/ \mathrm{m}^{2} ; \mathrm{E}: 0.10>$ adet $/ \mathrm{m}^{2}$ olarak değerlendirilmiştir.

\section{Bulgular ve Tartışma}

Çalışmalar havuç tarlalarındaki yabancı ot türlerini, yaygınlıklarını ve yoğunluklarını belirlemek amacı ile 2018-2019 üretim dönemini kapsayan 15 Ağustos 2018-15 Ekim 2019 tarihleri arasında yapılmış olup, elde edilen sonuçlar Çizelge 2'de verilmiştir.

Çizelge 2. Hatay ili havuç ekim alanlarında saptanan yabancı otların yaygınlık ve yoğunlukları

Table 2. Densities and frequencies of weed species determined in carrot fields in Hatay province

\begin{tabular}{|c|c|c|c|c|c|}
\hline Bilimsel Adı & Yerel Adı & Yaygınlık & Yoğunluk & Dönemi* & $\begin{array}{c}\text { Hayat } \\
\text { Formu } * *\end{array}$ \\
\hline \multicolumn{6}{|l|}{ Fam. AMARANTHACEAE } \\
\hline Amaranthus hybridus $\mathrm{L}$. & Melez horoz ibiği & OR & $\mathrm{D}$ & $\mathrm{Y}$ & TY \\
\hline Amaranthus retroflexus $\mathrm{L}$. & Horoz ibiği & OR & $\mathrm{C}$ & $\mathrm{Y}$ & $\mathrm{TY}$ \\
\hline Amaranthus spinosus $\mathrm{L}$. & Dikenli horoz ibiği & NR & $\mathrm{D}$ & $\mathrm{Y}$ & TY \\
\hline Amaranthus graecizans L. & Yatık horoz ibiği & NR & $\mathrm{D}$ & $\mathrm{Y}$ & TY \\
\hline Amaranthus palmeri S.Watson & Dev horoz ibiği & NR & $\mathrm{E}$ & Y & TY \\
\hline \multicolumn{6}{|l|}{ Fam. APIACEAE (Umbelliferae) } \\
\hline Ammi visnaga (L.) Lam. & Kürdan otu & NR & $\mathrm{E}$ & $\mathrm{Y}$ & TY (IY) \\
\hline Daucus carota $\mathrm{L}$. & Yabani havuç & NR & $\mathrm{E}$ & $\mathrm{K}$ & İY \\
\hline \multicolumn{6}{|l|}{ Fam. ASPLEPIADACEAE } \\
\hline Cynachum acutum $\mathrm{L}$. & Sütlü sarmaşık & NR & $\mathrm{E}$ & $\mathrm{Y}$ & ÇY \\
\hline \multicolumn{6}{|c|}{ Fam. ASTERACEAE (Compositae) } \\
\hline Anthemis arvensis $\mathrm{L}$. & Tarla köpek papatyası & $\mathrm{AR}$ & $\mathrm{E}$ & $\mathrm{K}$ & TY \\
\hline Anthemis chia $\mathrm{L}$. & Boylu papatya & $\mathrm{AR}$ & $\mathrm{E}$ & $\mathrm{K}$ & TY \\
\hline Calendula arvensis $\mathrm{L}$. & Portakal nergizi & NR & $\mathrm{E}$ & $\mathrm{K}$ & TY \\
\hline Carduus pycnocephalus L. & Saka dikeni & AR & $\mathrm{E}$ & $\mathrm{K}$ & TY (IY) \\
\hline Chrysanthemum segetum $\mathrm{L}$. & Sarı papatya & NR & $\mathrm{E}$ & $\mathrm{K}$ & TY \\
\hline
\end{tabular}


JOTAF/ Journal of Tekirdag Agricultural Faculty, 2019, 16(3)

Conyza canadensis (L.) Cronquist

Lactuca serriola $\mathrm{L}$.

Senecio vernalis Waldst. and Kit.

Senecio vulgaris $\mathrm{L}$.

Silybum marianum (L.) Gaertner

Sonchus arvensis L.

Sonchus oleraceus L.

Taraxacum serotinum (Waldst. and Kit.) Poir.

Xanthium strumarium L.

\section{Fam. BORAGINACEAE}

Heliotropium europaeum $\mathrm{L}$.

Fam. BRASSICACEAE

Capsella bursa-pastoris (L.) Medik.

Neslia paniculata (L.) Desv.

Ochtodium aegyptiacum (L.) DC.

Raphanus raphanistrum $\mathrm{L}$.

Sinapis alba L.

Sinapis arvensis L.

Thlaspi arvense $\mathrm{L}$.

\section{Fam. CARYOPHYLLACEAE}

Cerastium dichotomum $\mathrm{L}$.

Stellaria media (L.) Vill.

\section{Fam. CHENOPODIACEAE}

Chenopodium album $\mathrm{L}$.

Fam. CONVOLVULACEAE

Convolvulus arvensis L.

Ipomoea triloba $\mathrm{L}$.

\section{Fam. CYPERACEAE}

Cyperus rotundus $\mathrm{L}$.

\section{Fam. EUPHORBIACEAE}

Euphorbia chamaesyce L.

Euphorbia helioscopia L.

Mercurialis annua L.

\section{Fam. GERANIACEAE}

Erodium cicutarium (L.) L'Herit.

Geranum rotundifolium $\mathrm{L}$.

\section{Fam. LAMIACEAE}

Lamium amplexicaule $\mathrm{L}$.
Pire otu

Dikenli yabani marul

Kanarya otu

İmam kavuğu

Meryem dikeni

Eşek marulu

Adi eşek marulu

Aslan dişi

Domuz pitrağı

Boz ot

Çoban çantası

Toplu iğne hardalı

Çukurova hardalı

Yabani turp

Akhardal

Yabani hardal

Tarla akça çiçeği

Boynuz otu

Kuşotu

Sirken

Tarla sarmaşı̆̆ı

Pembe çiçekli akşam sefası

Topalak

Sütleğen

Güneş sütleğeni

Yer fesleğeni

Dönbaba

Turna gagası
NR

NR

NR

AR

NR

AR

NR

NR

NR

OR

NR

NR

NR

NR

NR

AR

NR

NR

NR

OR

OR

NR

ÇR

AR

NR

NR

NR

NR

NR

Ballıbaba

E

K

TY 


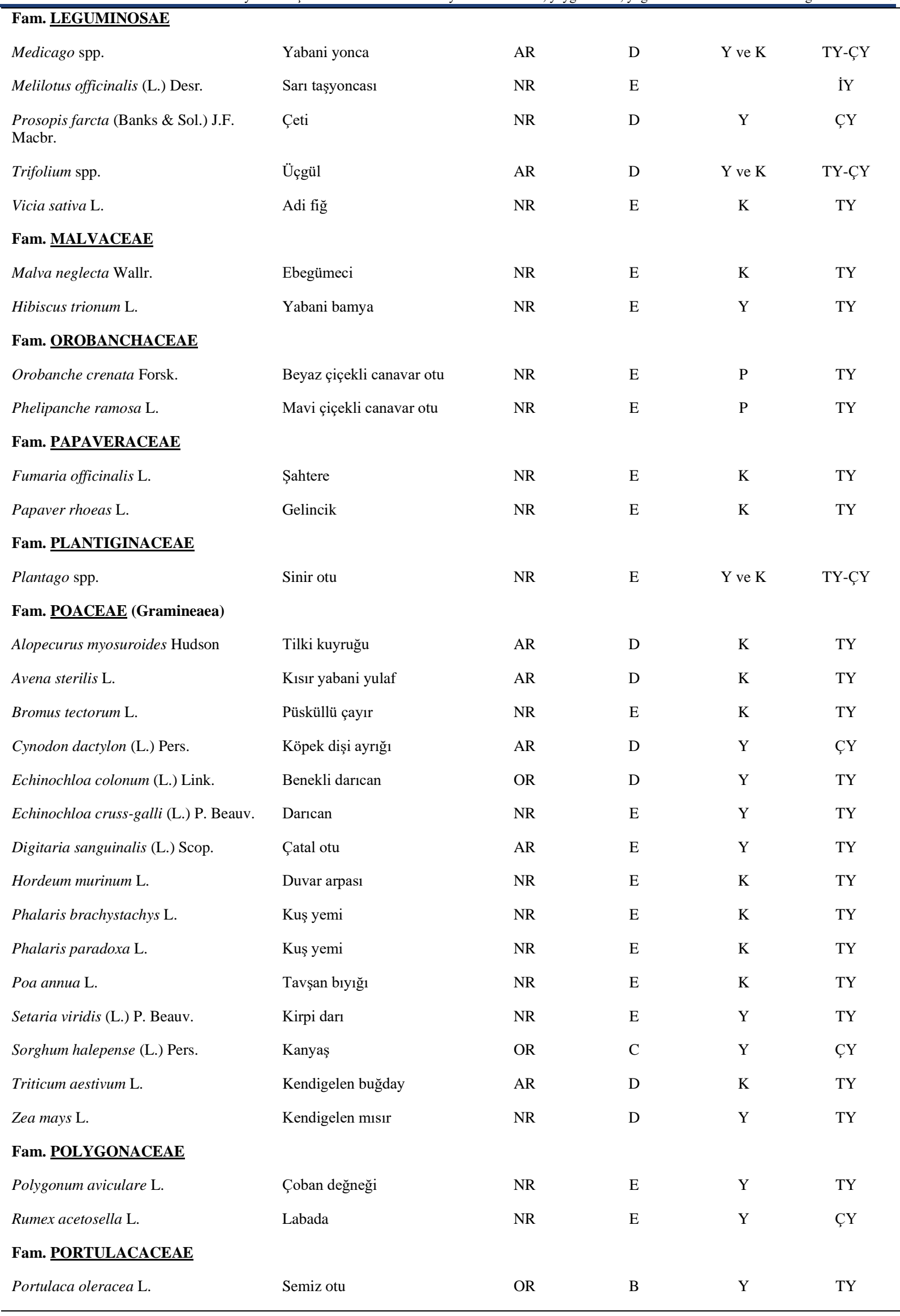




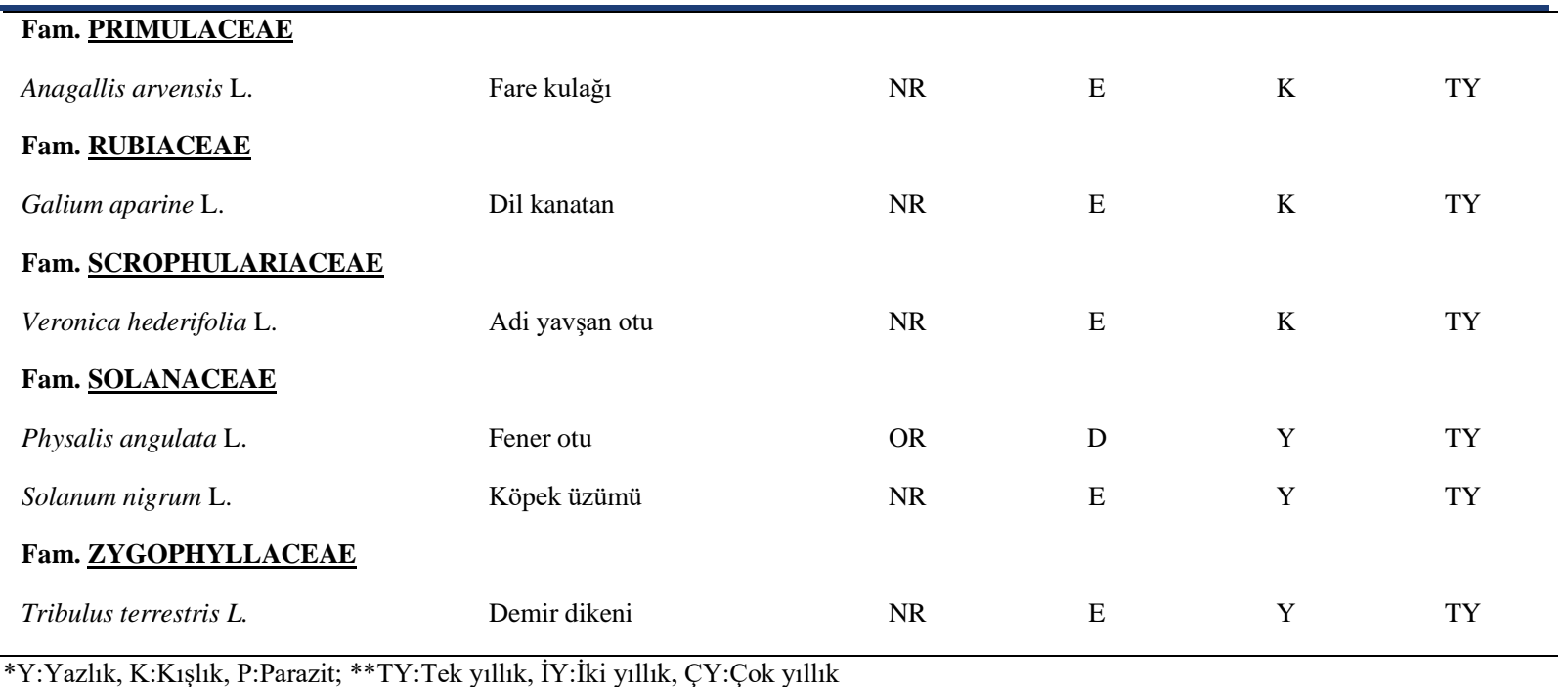

Hatay ili havuç alanlarında yapılan çalışmada 26 familya ve 66 cinse ait 78 yabancı ot türü saptanmıştır (Şekil 1). En fazla tür bulunan familyalardan Poaceae familyasında 15, Asteraceae familyasında 14 ve Brassicaceae familyasında ise 7 yabancı ot türü belirlenmiştir. Bu yabancı otların 2'si Parazit, 41'i Kışlık, 32'si Yazlık, 3'ü Yazlık-Kışlık türler olup, bunların da 16'sı dar yapraklı, 60'ı ise geniş yapraklıdır. Hayat sürelerine göre yabancı otların, 9’u Çok Yıllık (ÇY), Tek Yıllık (TY) (57 tür) ve İki Yıllık (IY) (3 tür) olup 3’ü TY-ÇY, 4’ü ise TY-IYY'dir. Yabancı otların yaygınlığı açısından bakıldığında Çok Rastlanan (ÇR) olarak; Cyperus rotundus (Topalak), Orta Rastlanan (OR) olarak; Amaranthus hybridus, Amaranthus retroflexus, Chenopodium album, Convolvulus arvensis, Echinochloa colonum, Physalis angulata, Portulaca oleracea, Sorghum halepense, Xanthium strumarium, Az Rastlanan (AR) olarak; Alopecurus myosuroides, Anthemis arvensis, Anthemis, chia, Avena sterilis, Carduus pycnocephalus, Cynodon dactylon, Digitaria sanguinalis, Euphorbia chamaesyce, Medicago spp., Senecio vernalis, Sinapis arvensis, Silybum marianum, Trifolium spp., Triticum aestivum bulunmuştur. Diğer yabancı otların yaygınlığı "NR" (54 tür) seviyesindedir.

Havuç tarlalarında belirlenen yabancı otların yoğunluğuna bakıldığında; sadece Cyperus rotundus (Topalak) "A" seviyesinde belirlenmiş olup, Portulaca oleracea (Semiz otu) "B" seviyesinde, Amaranthus retroflexus ve Sorghum halepense (kanyaş) "C" seviyesinde, Alopecurus myosuroides, Amaranthus graecizans, Amaranthus hybridus, Amaranthus spinosus, Avena sterilis, Chenopodium album, Convolvulus arvensis, Cynodon dactylon, Echinochloa colonum, Euphorbia chamaesyce, Medicago spp., Physalis angulata, Prosopis farcta, Silybum marianum, Triticum aestivum, Sinapis arvensis, Trifolium spp., Zea mays, Xanthium strumarium ise "D" seviyesinde bulunmuştur. Diğer yabancı otlar (55 tür) ise "E" seviyesinde olduğu hesaplanmıştır.

Havuç alanlarındaki gözlemler ve veriler değerlendirildiğinde; havuç ekiminin A ğustos ayının ortasında başlaması, daha sonra kademeli olarak Ocak ayına kadar devam etmesi nedeniyle ilk ekimlerde ağırlıklı olarak yazlık yabancı otlar daha sonrakilerde ise kışlık yabancı otlar görülmektedir. Üreticiler yabancı ot mücadelesinde öncelikle herbisit kullanmakta ancak, yabancı ot türlerinin çok olması ve özellikle ilk dönemde çok yoğun olması, ruhsatlı herbisit sayısının az ve etki spektrumunun dar olması nedeniyle oldukça zor durumda kalmaktadırlar. Ayrıca, ağır bünyeli tarlalarda yapılan salma sulama ve çapalama sorunun boyutunu daha da büyütmektedir. Yağışlı yıllarda yapılan geç ekimlerde yabancı ot sorunu kışlık yabancı otlarda da ön plana çıkmaktadır. Bu nedenle üreticiler özellikle dar yapraklı yabancı otlara karşı herbisit uygulamaktadırlar. Tüm yapılanlara rağmen yabancı otların mücadelesinde bir noktaya kadar başarılı olunmaktadır. 

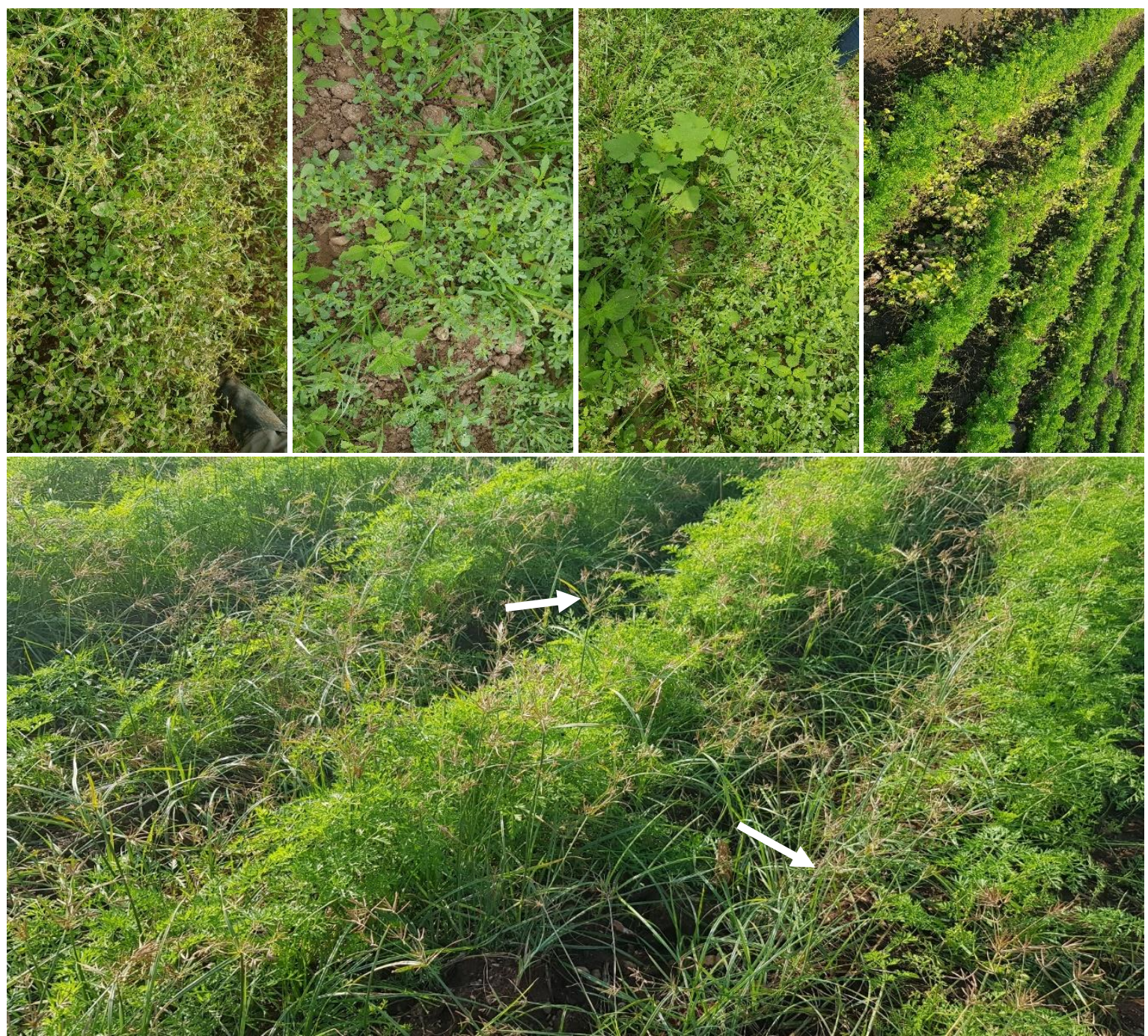

Şekil 1. Hatay ili havuç ekim alanlarında karşılaşılan farklı yabancı ot türleri. C. rotundus (topalak) yabancı ot türü (ok) sürvey alanlarında en yoğun tür olarak karşıllaşılmıştır.

Figure 1. Different weed species detected in surveyed carrot fields in Hatay province. Purple nutsedge (Cyperus rotundus) is the most common and frequently encountered weed species (arrows) in carrot fields

Öne çıkan yabancı otlardan Cyperus rotundus (topalak) rastlanma sıklı̆̆ı (ÇR) ve yoğunluğu (A) açısından en yüksek seviyede olduğu saptanmıştır. Ancak, çok yıllık bir bitki olan ve genellikle yumruları ile çoğalan topalağın gerek mekanik mücadele gerekse ruhsatlı herbisit bulunmamasından dolayı kimyasal mücadele ile kontrolu çok zor olup, hatta mümkün olamamakta, mekanik mücadele ise yetersiz kalmaktadır. Daha önceden maydanoz yetiştiriciliği yapılan aynı alanlardaki sürveylerde $C$. rotundus'un yoğunluğu $10 \mathrm{adet} / \mathrm{m}^{2}$ olarak bildirilmiştir (Telli ve Üremiş, 2010). Bu bölgede kayısı bahçelerinde yapılan diğer bir sürveyde $C$. rotundus 'un 5 adet $/ \mathrm{m}^{2}$ 'den daha fazla yoğunluğa ve \% 25-50 arasında rastlanma sıklığına sahip olduğuna dikkat çekilmektedir (Üremiş ve ark., 2013). Sertkaya ve ark. (2013) bu bölgedeki bağ alanlarında bulunan yabancı otlardan topalağın önemini belirtmektedirler. Diğer ürünlerde olduğu gibi bölgedeki fasulye alanlarında da $C$. rotundus yaygın ve yoğun olarak bildirilmekte ve mücadelesindeki zorluklardan bahsedilmektedir (Sertkaya ve ark., 2012). Bu çalışmada da topalağın rastlama sıklığının ve yoğunluğunun yüksek olması beklenen bir sonuç olarak değerlendirilmektedir.

Amaranthus hybridus, Amaranthus retroflexus, Chenopodium album, Convolvulus arvensis, Echinochloa colonum, Physalis angulata, Portulaca oleracea, Sorghum halepense, Xanthium strumarium rastlanma skklkları Orta Rastlanan (OR) arasında yer almaktadır. Pamukta (Kadıoğlu ve ark., 1993), maydanozda (Telli ve Üremiş, 2010), fasulyede (Sertkaya ve ark., 2013) ve soğanda (Kaya, 2016) bu yabancı otlar önemli olarak bildirilmiştir. Bunların arasında Portulaca oleracea'nın yoğunluğu "B" seviyesinde olarak bulunmuştur. Bu yabancı otlar yazlık ve tek yıllık bir yabancı otlar olup tohumları ile çoğalmaktadır. Özellikle salma sulama yapılan ve ağır bünyeli 
topraklarda oldukça önemli görülmekle birlikte mevcut herbisitlerle uygun bir mücadele yapıldı̆̆ında kontrol altına alınabilmektedir.

Sorghum halepense (kanyaş)'ye orta rastlama (OR) sıklığında rastlanması ve orta düzeyde yoğunlukta bulunması önemlidir. Her ne kadar kanyaş bitkisinin bölgedeki yaygınlık ve yoğunluğunun orta düzeyde olması iyi olarak değerlendirilmiş olsa da, yabancı otun dünyada en önemli ilk 10 yabancı ot arasında olmasının yanısıra istilacı karakterde ve anavatanlarından birinin bölgemiz olması göz önünde bulundurulacak önemli hususlardır. Kanyaş mücadelesinde kullanılabilecek ruhsatlı herbisitlerin olması ve bu herbisitlerin aynı zamanda diğer dar yapraklı yabancı otlara da etkili olması mücadele açısından önemli bir avantaj olarak kabul edilebilir. Yapılacak olan iyi bir mücadele planı ile kanyaşın baskı altında tutulabileceği düşünülmekle birlikte yine de çok dikkatli olmak gerekmektedir. Pamukta (Kadıŏlu ve ark., 1993), patateste (Sertkaya ve ark., 2009; Üremiş ve Uludağ, 2020) ve kayısıda (Üremiş ve ark., 2013) havuçta da olduğu gibi kanyaşın rastlanma sıklığı ve yoğunluğunun yüksekliğine dikkat çekilmektedir. Amaranthus retroflexus'a Sorghum halepense gibi orta rastlama (OR) sıklığında rastlanması ve orta düzeyde yoğunlukta olmasına rağmen mevcut mücadele yöntemleri ile başarılı bir şekilde kontrol edilebileceği düşünülmektedir. Üreticinin bu yabancı ottan fazla şikâyet etmemesi görüşümüzü desteklemektedir.

Kozmopolit, çok yıllık, yazlık ve geniş yapraklı bir yabancı ot olan Convolvulus arvensis' in yoğunluğunun "D" seviyesinde kalması durumu biraz rahatlatmaktadır, yoksa bu yabancı ota karşı havuçta kullanılabilecek bir herbisit olmaması ve çapalamanın da yeteriz kalması durumu zorlaştırabilecektir. Tarla sarmaşığının rekabetçiliği ve bulunduğu alanlarda basit bir ihmalde bile geri dönüşüme imkan vermeyecek ölçüde zarar verebilme özelliklerinde olabilmesini her zaman göz önüne alınmasını gerektirmekte olup aynı konu farklı ürünlerde bu bölgede yapılan başka sürveylerde de belirtilmektedir (Kadığlu ve ark., 1993; Sertkaya ve ark., 2009; Üremiş ve ark., 2009; Üremiş ve ark., 2013; Sertkaya ve ark., 2013; Soylu ve ark., 2017). Yapılan gözlemlerde tarla sarmaşı ̆̆ının rastlama sıklığı ve yoğunluğu bir diğer önemli yabancı ot olan kanyaşa yakın olduğu belirlenmiştir. Ayrıca, kış döneminde yapılan sürveyde tarla sarmaşığının Şubat 2019 sonu gibi çok erken dönemde bulunması dikkat çekici bir durumdur, genellikle Nisan ortalarından itibaren görülen bu yabancı otun bu kadar erken tarihte bulunması özellikle buğday üreticileri açısından endişe verici bir konu olarak değerlendirilmektedir. Özellikle 11 k geçen kış mevsiminde çok dikkatli olunması gerektiği ortadadır. Bu nedenle bu yabancı otun sıkı bir şekilde takip edilmesi gerekmektedir.

Diğer yabancı otların yaygınlık ve yoğunlukları yukarda bahsedilen yabancı otlara göre fazla olmalarına rağmen, yetiştiriciler tarafından gerekli kültürel önlemler, mekanik mücadele ve kimyasal mücadeleler ile bu yabancı otların potansiyel zararlarının üstesinden gelinme şansı bulunmaktadır. Xanthium strumarium (domuz pitrağı) ve Cynachum acutum (sütlü sarmaşık)'un havuçta kimyasal mücadelesine yönelik herbisit olmaması nedeniyle düşük yoğunlukta olmalarına rağmen verebileceği zarar düşünülerek üzerinde durulmasına ve takibine gerek bulunabileceği kanaatindeyiz.

$\mathrm{Bu}$ çalışmada önemli bulguların başında birçok tarlada yoğun olarak bulunan ve üreticinin mücadelesinde çaresiz kaldığı Cyperus rotundus'ların üzerinde saptanan ve yabancı otun biyolojik mücadelesinde kullanılma potansiyeli olan pas hastalık etmeni Puccinia romagnoliana Maire \& Sacc.'nın Kırıkhan (14 tarla), Reyhanlı (10 tarla) ve Kumlu (9 tarla) ilçelerinde bulunan havuç havuç alanlarındaki topalak bitkileri üzerinde \%33.3-47.6 yaygınlık ve \%42-85 bulaşma oranlarında bulunmasıdır (Şekil 2). Hastalık etmeni havuç bitkisi üzerinde herhangi bir hastalık belirtisine neden olmamıştır. Aynı tarlaya yapılan müteakip sürveylerde pas hastalık etmeninin enfeksiyonu sonucunda tarladaki topalak yoğunluğu ciddi şekilde düştüğü sonuçta hastalık etmenin topalak yaygınlığını önemli ölçüde baskı altına aldığı gözlenmiştir. Elde edilen bu gözlemin daha sonraki yapılacak detaylı biyolojik mücadele çalışmalar için önemli olduğu ve geleceğe yönelik yabancı otun biyolojik mücadelesi açısından umut verdiği düşünülmektedir. Ancak, konuyla ilgili detaylı çalışmalara ihtiyaç olduğu aşikardır. Hastalık etmenin ülkemizde varlığ 1 daha önceden yapılan çalışmada bildirilmiştir (Bahçecioğlu ve Kabaktepe, 2012). Etmenin topalak üzerinde biyolojik mücadele kapsamında kullanılma potansiyeline sahip olduğu önceden yapılmış çalışmalarda da bildirilmiştir (Bedi ve Sokhi, 1994; Gupta ve ark., 2003; Morales-Payan ve ark., 2005). Hindistan'da yapılan bir çalışmada Puccinia romagnoliana tarafından neden olunan pas hastalık çıkış enfeksiyonunun topalak yabancı otunun taze ağırlığında \%64, kuru ağırlığında \%56 oranında azalmaya neden olduğu, enfeksiyonun yabancı otun rizom ve sayısında \%34, ağırlığında ise \%83 oranında azalmaya neden olduğu bildirilmiştir (Bedi ve Sokhi, 1994). Benzer durum İsrail de yapılan çalışma ile teyit edilmiştir (Dinoor ve ark., 1994). 
Üremiş\& Soylu\& Kurt\& Soylu\& Sertkaya

Hatay ili havuç ekim alanlarında bulunan yabancı ot türleri, yaygınlıkları, yoğunlukları ve durumlarının değerlendirilmesi.
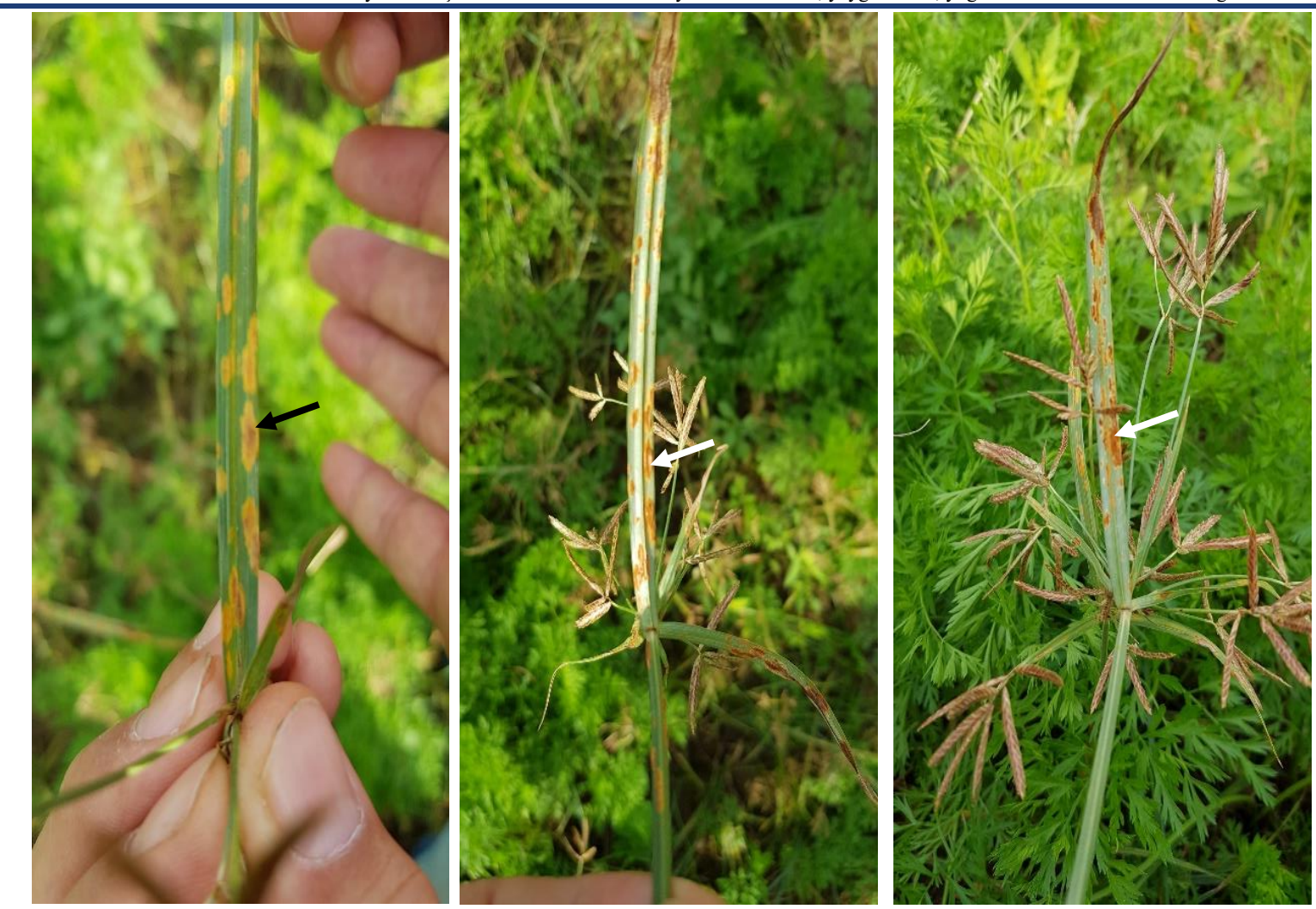

Şekil 2. Havuç tarlalarında en sık ve yoğunlukta karşılaşılan topalak (Cyperus rotundus) bitkisinin yaprak ve gövdelerinde biyolojik mücadele etmeni Puccinia romagnoliana tarafindan oluşturulan pas hastalık belirtileri (ok).

Figure 2. Typical rust disease symptoms (arrows) caused by biocontrol disease agent Puccinia romagnoliana on leaves and stems of purple nutsedge (Cyperus rotundus) which is the most common and frequently encountered weed species (arrows) in carrot fields

Yapılan çalışmada saptanan önemli bir konu parazit bitkilerdir. Bu parazit bitkiler Orobanche crenata (beyaz canavar otu, Şekil 3a ve b) ve Phelipanche ramosa (mavi çiçekli canavar otu, Şekil 3c)'dır. Topboğazı mıntıkasında Kırıkhan ilçesine ait havuç tarlasında saptanan parazit bitkiler havuç alanlarındaki ilk tespittir. Daha önceki yayınlarda buna ilişkin bilgiye rastlanılamamıştır. Çalışmada belirlenen iki canavar otu'da düşük rastlanma sıklığı ve yoğunluğuna sahiptirler. Ancak sadece iki tarlada bulunan canavar otlarının genel yaygınlık ve yoğunlukları düşük olmasına rağmen bulunduğu tarladaki özel yoğunluğu yüksek olup, beyaz çiçekli canavar otu "C" seviyesinde, mavi çiçekli canavar otu için " $\mathrm{D}$ ” seviyesindedir. Beyaz çiçekli canavar otunun ana konukçuları arasında havuç'un yanında bakla, mercimek ve nohut bulunmakta olup mavi çiçekli canavar otu için aynı şekilde havuç'un yanında domates, biber, patlıcan, tütün, kavun, patates, maydanoz ve bakla bulunmaktadır. Bu ürünler bu bölgede havuçla ekim nöbetine girdiği düşünüldüğünde çok dikkatli olunması gerekmektedir. Üreticiler bu konuda yeterli bilgiye sahip olmadıklarından görecekleri zararı hesap edememektedir (Şekil 3d ve e). Havuç üretiminde canavar otuna karşı kullanılabilecek herhangi bir kimyasal olmaması ve diğer mücadele yöntemlerin de çoğu zaman yetersiz kalması nedeniyle konuya hassasiyetle eğilip şu anda bölgede çok düşük olan yaygınlık ve yoğunluğun artmaması için gerekli tedbirlerin alınması gerekmektedir. 

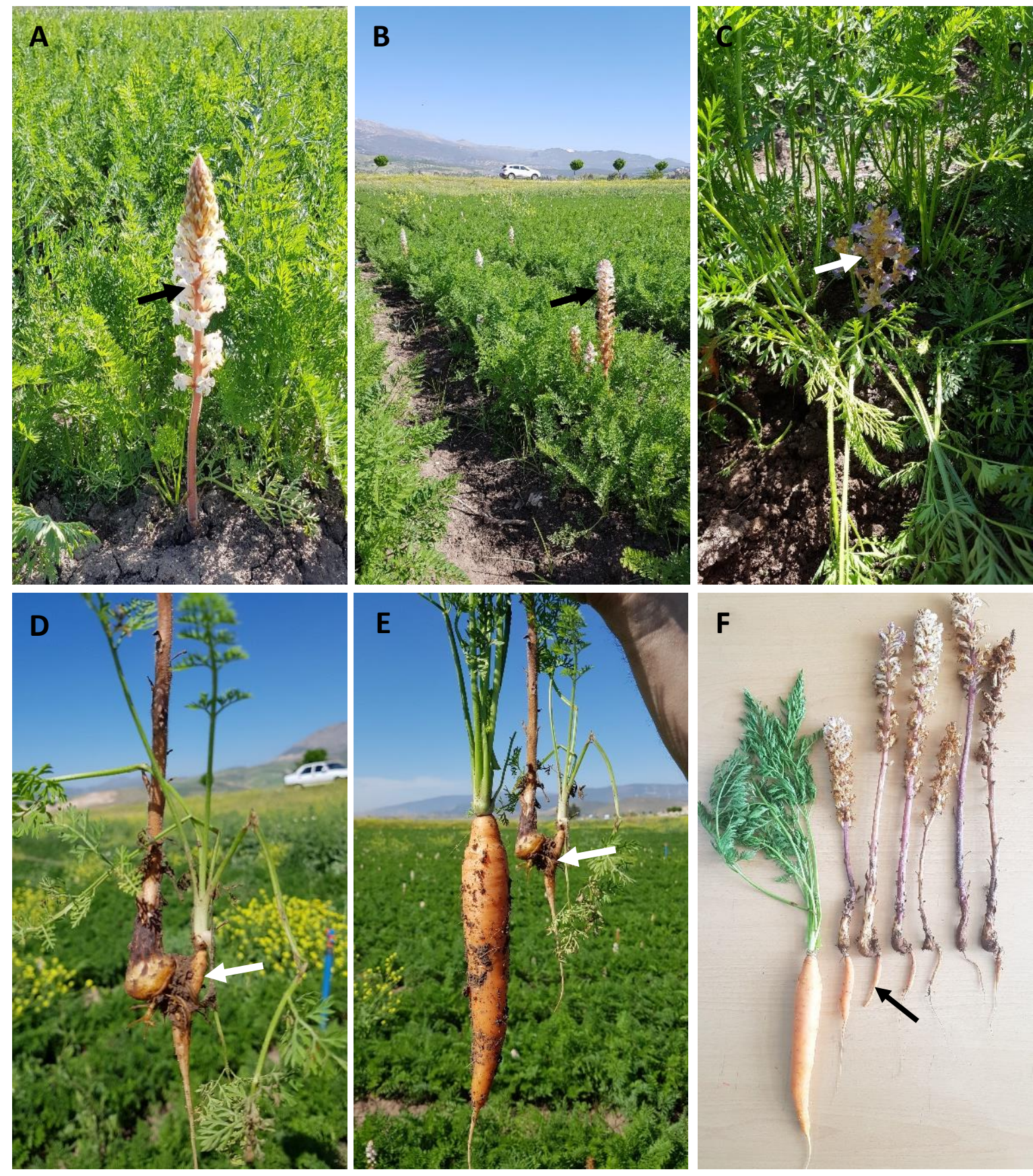

Şekil 3. Havuç alanlarında tespit edilen (A ve B) Orobanche crenata (beyaz canavar otu) ve (C) Phelipanche ramosa (mavi çiçekli canavar otu) [ok]. (D-F) Orobanche crenata (beyaz canavar otu) tarafından oluşturulan verim kaybı [ok] sağlıklı (E ve F) havuç meyvesi ile kıyaslanması ile açık bir şekilde görülmektedir.

Figure 3. Parasitic weed species (A and B) Orobanche crenata (bean broomrape) and (C) Phelipanche ramosa (hemp broomrape) in the surveyed carrot fields. (D-F) Typical yield losses caused by Orobanche crenata as evident on affected carrot roots (arrows) comparison to healthy carrot $(\mathbf{E}$ and $\mathbf{F})$ in same fields.

Bu çalışmada elde edilen önemli bulgulardan biri de havuç alanlarında ilk kez saptanan istilacı bir tür olan Amaranthus palmeri S. Watson'dur (Şekil 4). Türkiye'de ilk olarak 2014 yılında Doğu Akdeniz (Hatay ve Osmaniye)'de görülmüştür (Eren ve ark., 2016). Nasıl taşındı̆̆ı/bulaştığı konusu tam olarak bilinmemekle beraber ilk bulaşmadan sonra başka bölgelere muhtemelen yurtdışından ithal edilmiş hayvanların gübresi ile bulaştıktan sonra bölgelerde sulama suyu ve/veya tohumla taşındı̆̆ 1 tahmin edilmektedir. A. palmeri ilk olarak yol kenarı, sulama kanalları kenarı gibi tarım dışı alanlarda görülmekle birlikte zaman içerisinde turunçgil, pamuk, mısır, soya, 
Üremiş\& Soylu\& Kurt\& Soylu\& Sertkaya

Hatay ili havuç ekim alanlarında bulunan yabancı ot türleri, yaygınlıkları, yoğunlukları ve durumlarının değerlendirilmesi.

ayçiçeği, patates ve yer fıstığı alanlarında hızla yayılmaktadır (Turhan, 2017; Doğan ve ark., 2018; Altundağ, 2019). Mücadelesi oldukça zor, rekabet gücü ve zarar oranı yüksek, yayılıcı ve istilacı özelliklere sahip A. palmeri'nin ülkemizde Amik ovasında yer alan havuç tarlalarında ilk defa bu çalışma ile belirlenmiştir. Amaranthaceae familyasından erkek ve dişi çiçekleri farklı bitkilerde olan, adaptasyon yeteneği yüksek, istilacı, tohumla çoğalan, tek yıllık, yazlık, 2-3 m boylanabilen bitki 300.000 kadar tohum oluşturabilmektedir (Sellers ve ark., 2003; Steckel ve ark., 2004). Ancak Amik ovasında şimdilik yaygınlık ve yoğunluğu çok düşük bulunan bu yabancı ota karşı sahip olduğu özelliklerinden dolayı çok dikkatli olunması gerektiği bellidir.
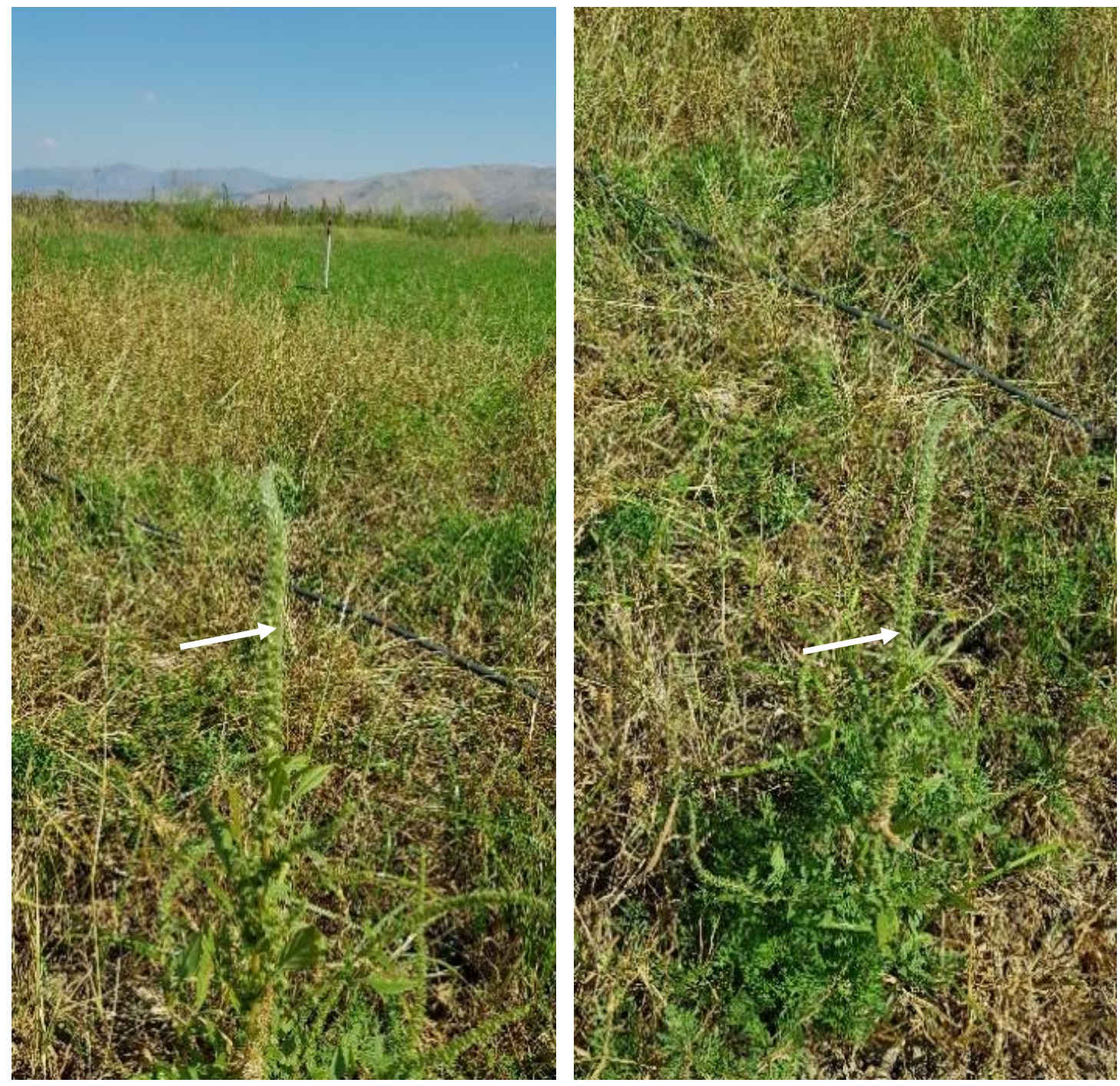

Şekil 4. Ülkemiz havuç alanlarında ilk kez tespit edilen yabancı ot türlerinden Amaranthus palmeri (dev horozibiği) [ok].

Figure 4. First record of invasive weed species Amaranthus palmeri (palmer amaranth) in carrot fields in Turkey

Ayrıca, Çalışmada, son yıllarda Akdeniz bölgesi tarım alanlarında hızlı bir yayılım gösteren ve önemli bir sorun olan Ipomoea triloba L. (pembe çiçekli akşam sefası)'ya (Şekil 5) Kırıkhan ilçesinde rastlanılmıştır. Ülkemizde Ipomoea stolonifera ve I. sagittata tarım dışı alanlarda, I. purpurea ve I. triloba ise özellikle tarım alanlarında bulunmaktadır. Ülkemizde Ipomoea triloba ilk olarak Antalya ili pamuk üretim alanlarında bulunmuş olup istilacı özelliği nedeniyle çok hızlı gelişmekte ve kısa zamanda kültür bitkisini tamamen sarmakta, bunun sonucunda da kültür bitkisinin gelişimini engellemektedir (Yazlık ve ark., 2018). Akdeniz bölgesinde hızla yayılmakta olup başta pamuk, mısır, domates, şekerpancarı, soya ve turunçgiller gibi pek çok üründe büyük zararlara neden olan Ipomoea triloba daha önce ülkemiz havuç yetiştiriciliği yapılan alanlarda saptanmamıştır. Bu türün Amik ovasındaki havuç dışında diğer yazlık ürünlerde de hızla yayılabilme potansiyelinde olduğu ve gelecekte bu alanlarda büyük sorunlara neden olabileceği konusunda ciddi endişeler bulunmaktadır. 

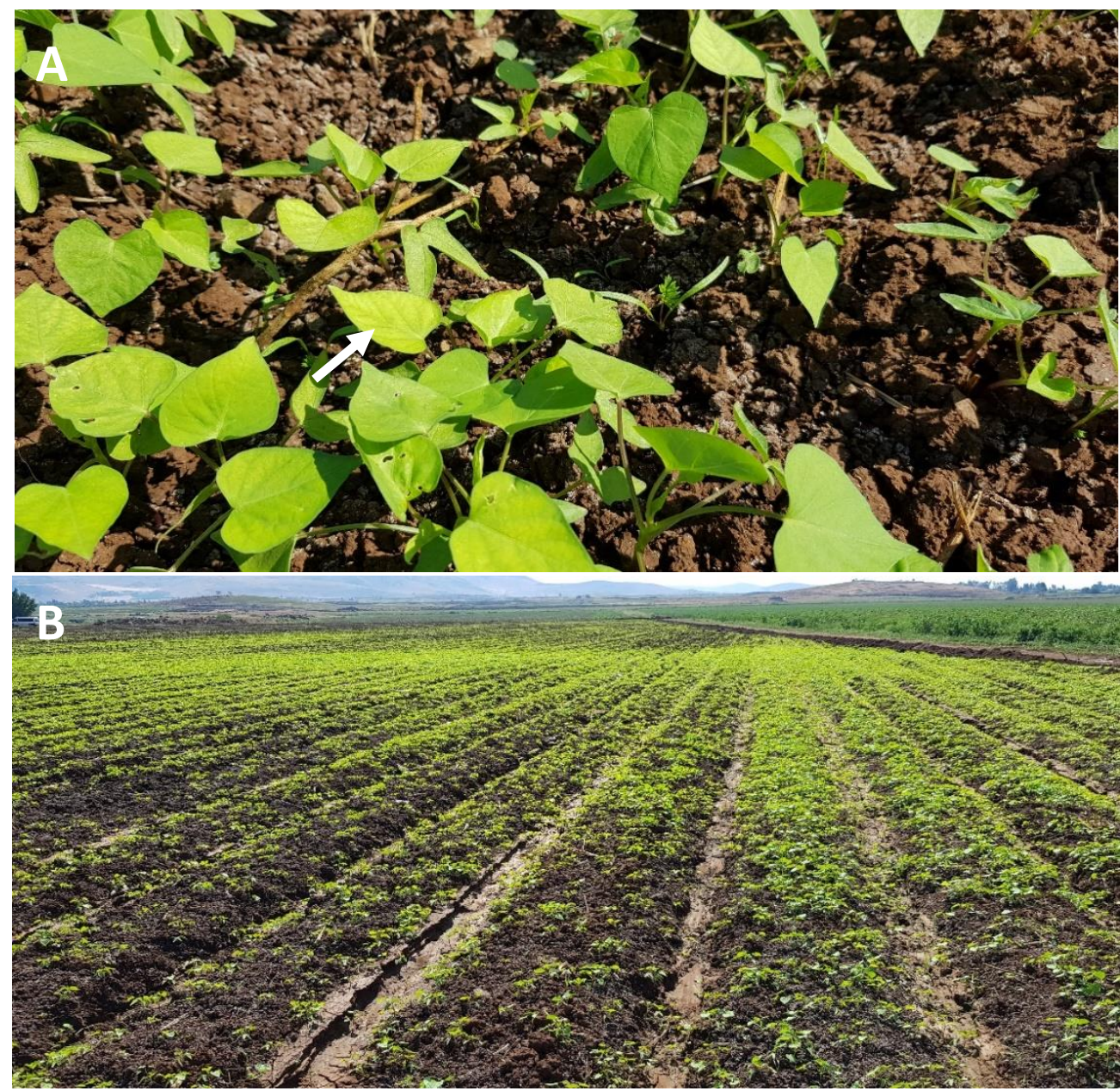

Şekil 5. (A) Havuç ekim alanlarında ilk kez tespit edilen yabancı ot türlerinden pembe çiçekli akşamsefası Ipomoea triloba (ok). (B) Yoğun şekilde çıkış yapmış Ipomoea triloba 'lı havuç tarlasından genel görünüşü

Figure 5. (A) First record of Ipomoea triloba L. (three-lobe morning glory, large arrow) in the surveyed carrot (small arrow) fields. (B) General appearance of intensively occupied carrot fields by Ipomoea triloba $\mathrm{L}$.

Türkiye'de havuç alanlarında yapılan bir adet yabancı ot sürveyine rastlanılabilmiştir. Bu çalışma 19881991 yılları arasında Ankara'da yürütülmüştür. Havuç alanlarında yapılan sürveylerde 34 yabancı ot türü saptanmış ve bunlar içerisinde en yaygın ve yoğun olarak bulunan üç tür, sırasıyla; Amaranthus retroflexus (\% 93,4 ve 2,78 adet $\left./ \mathrm{m}^{2}\right)$, Portulaca oleracea $\left(\% 89,1\right.$ ve 2,65 2,78 adet $/ \mathrm{m}^{2}$ ) ve Chenopodium album (\% 86,6 ve 3,19 2,78 adet $/ \mathrm{m}^{2}$ ) (Erciş ve ark., 1995)'dur. Yapılan çalışmalar arasındaki benzerlik görülmektedir. Bu yabancı otlar iki çalışmada da yaygınlık ve yoğunluk bakımından önde gelmektedir. Ancak, bu çalışmada saptanan yabancı ot tür sayısı daha fazla olmasında çalışmanın farklı ekolojilerde yapılması ve yetişme dönemlerindeki farklılıklardan ileri geldiği düşünülmektedir.

Sonuç olarak Türkiye'nin önemli havuç üretim alanlarında olan Hatay'da yapılan sürvey çalışmasında belirlenen yabancı otların yoğunluğuna bakıldığında; "A" seviyesinde sadece Cyperus rotundus (Topalak), "B" seviyesinde Portulaca oleracea (Semizotu), "C" seviyesinde Amaranthus retroflexus ve Sorghum halepense (Kanyaş) bulunmuştur. Diğer yabancı otların "D” (19 tür) ve“E” (55 tür) seviyesinde olduğu hesaplanmıştır. Yabancı otların yaygınlığı açısından bakıldığında Çok Rastlanan (ÇR) olarak; Cyperus rotundus (Topalak), Orta Rastlanan (OR) olarak; Amaranthus hybridus, Amaranthus retroflexus, Chenopodium album, Convolvulus arvensis, Echinochloa colonum, Physalis angulata, Portulaca oleracea, Sorghum halepense, Xanthium strumarium) bulunmuştur. Diğer yabancı otların yaygınlığı Az Rastlanan “AZ” (14 tür) ve "NR" (54 tür) seviyesindedir. Bunların arasında Cyperus rotundus (Topalak) yaygınlık ve yoğunluk bakımından en önde gelmekte olup etkili bir kimyasalın olmaması nedeniyle mücadelesinde üretici çaresiz kalmaktadır. Ancak üzerinde yoğun ve şiddetli olarak pas hastalık etmeni Puccinia romagnoliana enfeksiyonu tespit edilmiştir. 
Hastalık etmeninin saptandığı zamandan sonraki dönem içerisinde aynı tarlada hastalığın topalakları önemli ölçüde baskı altına aldığı gözlenmiştir.

Ayrıca, havuç alanlarında yaygınlık ve yoğunluğu şimdilik düşük olan Orobanche crenata (beyaz canavar otu) ve Phelipanche ramosa (mavi çiçekli canavar otu) bulunmuştur. Bu parazit bitkilerden kaynaklanan kalite ve verim düşüklüğü saptanmış olması ileriye yönelik ciddi endişeye neden olmaktadır. Bu çalışmada elde edilen önemli bulgulardan biri de Amik ovası havuç alanlarında ilk kez saptanan istilacı bir tür olan Amaranthus palmeri S. Watson ve Ipomoea triloba L.'dır. Mücadelesi oldukça zor, rekabet gücü ve zarar oranı yüksek, yayılıcı ve istilacı özelliklere sahip bu yabancı otların Amik ovasındaki yaygınlık ve yoğunluğu şimdilik çok düşük bulunmuştur. Ancak, bu yabancı ota karşı sahip olduğu özelliklerinden dolayı çok dikkatli olunması gerektiği ortadadir.

\section{Tessekkür}

Bu çalışma Hatay Mustafa Kemal Üniversitesi, Bilimsel Araştırma Projeleri Komisyonunca (MKU BAP18.M.069 ) desteklenmiştir. 


\section{Kaynakça/References}

Aksoy, E. ve Pekcan, V. 2014. Canavar otları (Orobanche spp., Phelipanche spp.) ve Mücadelesi. Gıda, Tarım ve Hayvancılık Bakanlığı Tarımsal Araştırmalar ve Politikalar Genel Müdürlüğü Bitki Sağlığı Araştırmaları Daire Başkanlığı Yayınları, Ankara, 80s.

Altundağ, B.C. 2019. Turunçgil alanlarında kullanılan farklı toprak herbisitlerinin Amaranthus palmeri’ye karşı etkinliklerinin belirlenmesi. Yüksek Lisans Tezi, Adnan Menderes Üniversitesi Fen Bilimleri Enstitüsü, Bitki Koruma Anabilim Dalı, 43s.

Anonim 2017. TUIKK Bitkisel Üretim İstatistikleri, Hatay. https://biruni.tuik.gov.tr/medas/?kn=92\&locale=tr (Erişim tarihi:14.06.2019).

Anonymous, 2017. FAOSTAT, Food and Agriculture Organization of the United Nations (FAO). http://www.fao.org.tr (Erişim tarihi: 14.08.2019).

Bahçecioğlu, Z., and Kabaktepe, S. 2012. Checklist of rust fungi in Turkey. Mycotaxon 119: 494.

Bedi, J.S., and Sokhi. S.S. 1994. Puccinia romagnoliana rust. A possible biological control agent for purple nutsedge. Indian Journal of Plat Protection, 22: 217-8.

Bhullar, M.S., Kaur, T., Kaur, S., and Yadav, R. 2015. Weed management in vegetable and flower crop-based systems. Indian Journal of Weed Science, 47 (3): 277-287.

Bora, T., ve Karaca, İ. 1970. Kültür Bitkilerinde Hastalık ve Zararlıların Ölçülmesi. Ege Üniversitesi, Ziraat Fakültesi Yardımcı Ders Kitabı Yayın No: 167, İzmir, 43s.

Çabuk, T.Ş. 2014. Ankara ili havuç (Daucus carota L. subsp. sativus) üretim alanlarında verimi ve kaliteyi olumsuz yönde etkileyen sistemik hastalıkların araştırılması. Yüksek Lisans Tezi, Namık Kemal Üniversitesi, Fen Bilimleri Enst. Bitki Koruma ABD, 51 s.

Davis, P.H., 1965-1988. Flora of Turkey and the East Aegean Islands. Edinburgh at the University Press, Volume 1-10.

Dinoor, A., Boyle, C., Aust, J.H., and Eshed, N. 1994. Biological control of purple nutsedge (Cyperus rotundus) by rust (Puccinia romagnoliana): The effect of temperature on the latent period of the rust. Phytoparasitica, 22:83-84.

Doğan, M.N., Ertem, M., ve Boz, Ö. 2018. Amaranthus palmeri - Türkiye için yeni bir yabancı ot türü. Türkiye VII. Bitki Koruma Kongresi, (14-17 Kasım 2018, Muğla) Bildiriler, sayfa: 118.

Erciş, A., Taştan, B., Yanmaz, R., ve Demir, K. 1995. Ankara ili havuç ekim alanlarında sorun olan yabancıotların yayılışı, yoğunluğu, ve mücadelesi üzerinde araștırmalar. Zirai Mücadele Araștırma Yıllığı 26-27: 148-149.

Eren, Ö., Doğan, M.N., Boz, Ö., Türkseven, S., and Özcan, R. 2016. Amaranthus palmeri S. Wats. (Raab-Straube, E. Von., Raus, T. Eds), Willdenowia, 46: 423-441.

Gupta, V.P., Kumar, V., Mishra, R.K., and Thiagarajan V. 2003. Puccinia romagnoliana Marie \& Sacc. - a potential bioherbicide agent for biocontrol of purple nutsedge (Cyperus rotundus L.) in mulberry. Journal of Phytopathology, 150(4-5): 263-270.

Güncan, A. 2016. Yabancı Otlar ve Mücadele Prensipleri. (Güncelleştirilmiş ve İlaveli Altıncı Baskı), Selçuk Üniversitesi Ziraat Fakültesi, Konya, 311s.

Kadıoğlu, İ., Uluğ, E., and Üremiş, İ. 1993. Akdeniz bölgesi pamuk ekim alanlarında görülen yabancıotlar üzerinde araştırmalar. Türkiye I. Herboloji Kongresi (3-5 Şubat 1993, Adana) Bildiriler, 151-156.

Karaca, M. 2010. Yatık gökbaș (Centaurea depressa Bieb.) ve kokarot (Bifora radians Bieb.)'un bazı biyolojik özellikleri ve Konya yöresinde buğdayda ekonomik zarar eşiklerinin tespiti. Doktora Tezi, Selçuk Üniversitesi Fen Bilimleri Enstitüsü, Bitki Koruma Anabilim Dalı, $149 \mathrm{~s}$

Kaya, H. 2016. Hatay ili soğan üretim alanlarında görülen yabancı otların yaygınlık ve yoğunlukları ile mücadelesine yönelik çalışmalar. Yüksek Lisans Tezi, Hatay Mustafa Kemal Üniversitesi Bitki Koruma Anabilim Dal1, 95s.

Kurt, S., Soylu, E.M., Soylu, S., and Tok, F.M. 2004. First report of crater rot caused by Rhizoctonia carotae on carrots in Turkey. Plant Pathology, 54: $251-252$.

Morales-Payan, J.P., Charudattan, R., and Stall, W.M. 2005. Fungi for biological control of weedy Cyperaceae, with emphasis on purple and yellow nutsedges (Cyperus rotundus and C. esculentus). Outlooks on Pest Management, 16:148-155

Munro, D. B., and Small, E. 1997. Vegetables of Canada. National Research Council, Ottowa, Ontorio.

Odum, E.P. 1971. Fundamentals of Ecology. W.B. Saunders Company, Philadelphia, London, Toronto. 574p.

Oerke, E.C., Dehwe, H.W., and Weber, A. 1994. Crop Production and Crop Protection - Estimated Losses in Major Food and Cash Crops. Elsevier Science, Amsterdam, 808p.

Ojedo, P.A.V., and Garay, C.R.E. 2017. Critical period of weed interference in carrot crop. Investigación Agraria, 19 (2): $77-85$

OMAFRA, 2008. Ontario Ministry of Agriculture, Food and Rural Affairs, Guide to Weed Control 2008-2009. Publication 75. Toronto, Canada: Queen's Printer for Ontario, 380p.

Orel, E. 1996. Çukurova bölgesi buğday ve mısır ekim alanlarında bazı ekolojik faktörlerin göstergesi olabilecek yabancı ot türlerinin saptanması. Yüksek Lisans Tezi, Çukurova Üniversitesi Fen Bilimleri Enstitüsü, Bitki Koruma Anabilim Dalı, 133s.

Özer, Z., Kadioğlu, İ., Önen, H., ve Tursun, N. 1998. Herbaryum Yapma Teknikleri ve Yabancı Ot Teşhis Yöntemleri. Gaziosmanpaşa Üniversitesi, Ziraat Fakültesi Yayınları No: 20, Tokat, 214s.

Pamukoğlu, Z. (2011). Kahramanmaraş Kırmızı Biber Alanlarında Sorun Olan Yabancı Otlar ve Bunlarla Mücadelede Kritik Periyodun Belirlenmesi. Yüksek Lisans Tezi, Kahramanmaraş Sütçü İmam Üniversitesi, Fen Bilimleri Enstitüsü, Bitki Koruma Anabilim Dalı, 47s.

Peters, S. 2006. Carrots: Enjoyed by Kids of All Ages. The Cutting Edges, Newsletter 59. 
Üremiş\& Soylu\& Kurt\& Soylu\& Sertkaya

Hatay ili havuç ekim alanlarında bulunan yabancı ot türleri, yaygınlıkları, yoğunlukları ve durumlarının değerlendirilmesi. Rubatzky, V.E., Quiros, C.F., and Simon, P.W. 1999. Carrots and related vegetable Umbelliferae . CAB Publishing Company, 294p.

Safadi, B. 2008. Characterization and distribution of Daucus species in Syria. Biologia, 63 (2): 177-182.

Sellers, B.A., Smeda, R.J., Johnson, W.G., Kendig, J.A., and Ellersieck, M.R. 2003. Comparative growth of six Amaranthus species in Missouri. Weed Science, 51: 329-333.

Sermenli, T. 2012. Önemli bir üretim bölgesi olan Hatay Kırıkhan'da havuç (Daucus carota L.) yetiştiriciliği. 9. Sebze Tarımı Sempozyumu (12-14 Eylül 2012, Konya) Bildiriler, 266- 271.

Sertkaya, G., Üremiş, İ., Sertkaya, E., Kaya, K., ve Çalışkan, M.E. 2009. Amik ovasında patates alanlarındaki yabancı ot türlerinin yoğunlukları ile bazı önemli patates virüsleri ve vektörleri yönünden araştırılması. Türkiye VIII. Tarla Bitkileri Kongresi (19-22 Ekim 2009 , Antakya/Hatay) Bildiriler, 143-147.

Sertkaya, E., Soylu, S., Üremiş, İ., Bozkurt, İ.A., ve Sertkaya, G. 2012. Hatay ili fasulye (Phaseolus vulgaris L.) ekim alanlarında görülen bitki koruma sorunları. 9. Ulusal Sebze Tarımı Sempozyumu (12-14 Eylül 2012, Konya) Bildiriler, 179-184.

Sertkaya, G., Yıldırım, A.E., Üremiş, İ., ve Sertkaya, E. 2013. Hatay ili bağ alanlarında bazı nepovirüslerin araştırılması. MKÜ Ziraat Fakültesi Dergisi, 18 (2): 39-46.

Sertkaya, G. 2014. Hatay ili havuç alanlarında fitoplazmaların araştırılması. Türkiye V. Bitki Koruma Kongresi (3-5 Şubat 2014 Antalya) Bildiriler, 279.

Steckel, L.E., Sprague, C.L., Stoller,E.W., and Wax, L.M. 2004. Temperature effects on germination of nine Amaranthus species. Weed Science, 52: 217-221.

Soylu, S., Kurt, Ş. Soylu, E.M, and Tok, F.M. 2005. First report of Alternaria leaf blight caused by Alternaria dauci on carrot in Turkey. Plant Pathology, 54: 252.

Soylu, S., Sertkaya, E., Üremiş, İ., Bozkurt, İ.A., ve Kurt, Ş. 2017. Hatay ili marul (Lactuca sativa L.) ekim alanlarında görülen önemli hastalık etmenleri, zararlı ve yabancı ot türleri ve yaygınlık durumları. MKÜ Ziraat Fakültesi Dergisi, 22 (1): 23-33.

Swanton, C.J., O’Sullivan, J., and Robinson, D.E. 2010. The critical weed-free period in carrot, Weed Science, 58 (3): $229-233$.

Telli, S., ve Üremiş, İ. 2010. Hatay’da maydanoz yetiştiriciliğinde karşılaşılan bitki koruma sorunları ve çözüm önerileri. MKÜ Ziraat Fakültesi Dergisi, 15 (1): 39-48.

Turhan, G. 2017. Amaranthus palmeri'nin mücadelesinde kullanılabilecek herbisitlerin belirlenmesi. Yüksek Lisans Tezi, Adnan Menderes Üniversitesi Fen Bilimleri Enstitüsü, Bitki Koruma Anabilim Dalı, $71 \mathrm{~s}$.

Tülek, S. 2010. Ankara ili havuç alanlarında görülen fungal hastalıkların belirlenmesi ve yaygınlık oranlarının saptanması. Yüksek Lisans Tezi, Ankara Üniversitesi, Fen Bilimleri Enst. Bitki Koruma Anabilim Dalı, 79 s.

Uluğ, E., Kadığlu, İ., ve Üremiş, İ. 1993. Türkiye’nin Yabancı Otları ve Bazı Özellikleri. T.K.B. Adana Zirai Mücadele Araştırma Enstitüsü, Yay. No: 78, Adana, $513 \mathrm{~s}$

Uludag, A., Uremis, I., and Arslan, M. 2018. Biological Weed Control, Non-Chemical Weed Control, (Eds.: Jabran, K, Chauhan BS, Academic Press, UK, pp 115-132.

Uygur, F.N. 1985. Untersuchungen zu Art und Bedeutung der Verunkrautung in der Çukurova unter Besonderer Berücksichtigung von Cynodon dactylon (L.) Pers. und Sorghum halepense (L.) Pers. PLITS 1985/3 (5), Stuttgart, 169p.

Uysal, N. 2012. Konya ili Kadınhanı kasabasındaki havuç depolarında görülen fitopatolojik sorunlar. Yüksek Lisans Tezi, Selçuk Üniversitesi, Fen Bilimleri Enst. Bitki Koruma Anabilim Dalı, 99 s.

Uremis, I., Calıskan, M.E.., Uludag, A. and Calıskan, S., 2009. Weed management in early-season potato production in the Mediterranean conditions of Turkey. Bulgarian J. Agric. Sci., 15 (5): 423-434.

Üremiş, İ, Sertkaya, E., Sertkaya, G., ve Yıldırım, A.E. 2013. Hatay ili kayısı bahçelerinde bulunan yabancı ot türlerinin, yaygınlıklarının ve yoğunluklarının belirlenmesi. MKÜ Ziraat Fakültesi Dergisi, 18 (2): 47-54.

Üremiş, İ. ve Uludağ, A., 2020. Patateste Yabancı Otlar ve Mücadelesi. (Patates, Ed. Çalışkan, M.E.). Tarım Türk Dergisi Yayınları, İzmir, sayfa: $98-111$.

Vural, H., Eşiyok, D., and Duman, İ. 2000. Kültür Sebzeleri (Sebze Yetiştirme). Ege Üniversitesi Basımevi, Bornova-İzmir, 440s.

William, R.D., and Warren, G.F. 1975. Competition between purple nutsedge and vegetables. Weed Science, 23: $317-323$.

Yanmaz, R. 1994. Havuç yetiştiriciliği. Standard Dergisi, 34: 21-22.

Yazlık, A., Uremis, I., Uludag, A., Uzun, K., Senol, S.G., and Keskin I. 2018. Ipomoea triloba: an alien plant threatening many habitats in Turkey. Eppo Bulletin, 48: 589-594.

Zimdahl, R.L. 2018. Fundamentals of Weed Science, $5^{\text {th }}$ Edition, Academic Press, UK. 758p. 